\title{
Use of Botulinum Toxin Type A Injection Under Ultrasonographic Guidance for Management of Parotid Sialocele: A Case Report and Literature Review
}

\section{Byung Yeun Kwon, Hak Soo Kim, \\ Dong Hwi Kim, Jung Ho Lee, Young Joon Jun, Young Jin Kim}

Department of Plastic and Reconstructive Surgery, Bucheon St. Mary's Hospital, College of Medicine, The Catholic University of Korea, Bucheon, Korea

No potential conflict of interest relevant to this article was reported.
Sialocele formation is a recognised complication of parotid surgery. Most cases resolve after conservative therapy consisting of pressure dressing, fasting, and repeated aspiration. However, some cases are resistent to such treatment and require further intervention. In this report, we present the method of botulinum toxin (BTX) injection into the parotid gland under ultrasonographic guidance along with atropine injection. A 63-year-old female underwent excision of a pleomorphic adenoma abutting an accessory parotid gland. Sialocele formation persisted after almost 3 weeks of conservative therapy. BTX A was given under ultrasonographic guidance and the sialocele disappeared after two doses of treatment. BTX injection under ultrasonographic guidance was thus a safe and effective method for treating persistent sialocele.

Keywords Botulinum toxins, Cysts, Parotid diseases

\section{INTRODUCTION}

A sialocele is an accumulation of saliva after an injury to the parotid gland duct or parenchyma [1]. The most common cause is the disruption of the parenchyma or parotid gland duct secondary to trauma, but it is also common after parotid surgery [1]. We present a case of parotid sialocele after surgical excision of a pleomorphic adenoma of the parotid gland, successfully treated with botulinum toxin (BTX) injection under ultrasonographic guidance.

\section{CASE REPORT}

A 63-year-female pateient presented with a swelling in the middle portion of the right cheek. Computed tomography imaging re-

Received: Jun 14, 2017 Accepted: Jun 27, 2017

Correspondence: Young Jin Kim Department of Plastic and Reconstructive Surgery, Bucheon St. Mary's Hospital, College of Medicine, The Catholic University of Korea, 327 Sosa-ro, Wonmmi-gu, Bucheon 14647, Korea. E-mail: psyjkim@catholic.ac.kr

Copyright () 2017 The Korean Society for Aesthetic Plastic Surgery.

This is an Open Access article distributed under the terms of the Creative Commons Attribution Non-Commercial License (http://creativecommons.org/licenses/by-nc/4.0/) which permits unrestricted non-commercial use, distribution, and reproduction in any medium, provided the original work is properly cited. $\quad w w w . e-a a p s . o r g$ vealed a well-defined, oval-shaped mass overlying the right masseter muscle, abutting the right parotid gland (Fig. 1). Fine-needle aspiration cytolgy confirmed pleomorphic adenoma. The patient underwent surgical excision through a mid-cheek incision. Intraoperatively, the tumor was found to be in contact with the right parotid gland lying on the masseter muscle. The tumor was meticulously excised while preserving the parotid fascia and main parotid gland but micro-injury to the parenchyma or duct could not be completely ruled out (Fig. 2). A Jackson-Pratt (JP) drain was placed subfascially. The JP drainage count continued to be over $20 \mathrm{~mL}$ after the tenth postoperative day, and the amylase level of the fluid was found to be over 20,000 U/L. The JP drain was removed at 2 weeks postoperatively to prevent infection and negative pressure on the gland structure that might aggravate the leakage of the parotid gland. Conservative compressive dressing with fasting was applied for 3 weeks postoperatively, but consistent swelling of the cheek and clear discharge from the JP site did not improve. The usage of BTX was considered, given the refractory response to conservative management. Two doses of BTX type A (Meditoxin; Pacific Pharmaceuticals Co., Ltd., Seoul, Korea) of 100 units in total were administered percutaneously under ultrasonographic guidance to avoid vessel or nerve injury in the parotid region around the sialocele 7 days apart (Fig. 3). An antisialogogue drug, atropine, was also concomitantly administered, in order to further inhibit 


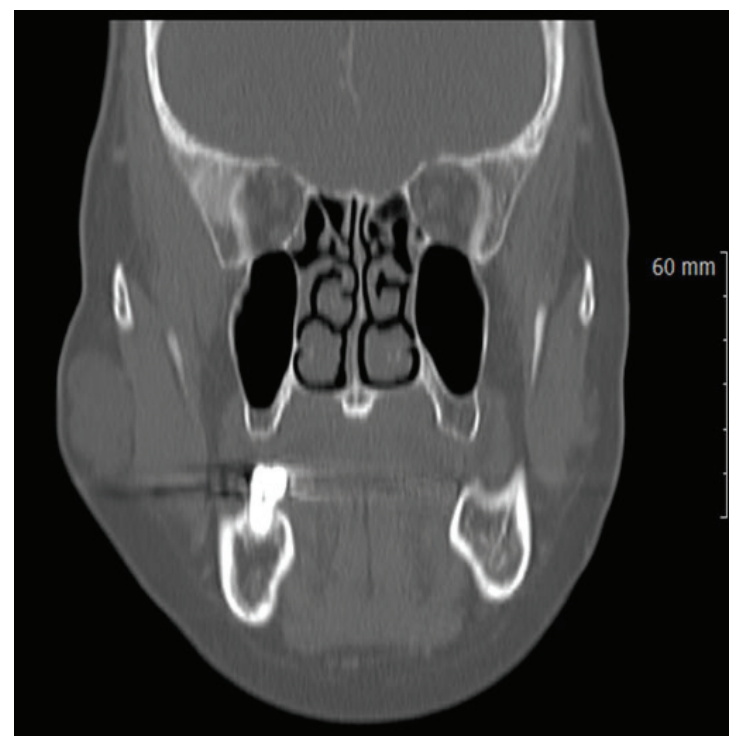

Fig. 1. Computed tomographic imaging of the face demonstrating an oval-shaped mass in the right mid-cheek region.

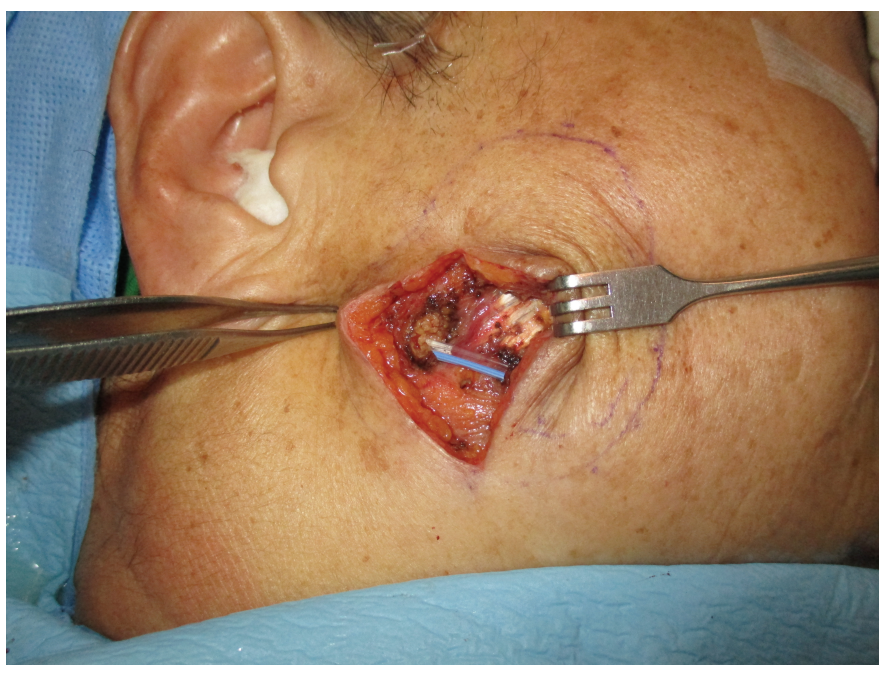

Fig. 2. Intraoperative findings after tumor excision: the main parotid gland abutting the mass.

salivary secretion by the parasympathetic nerve until the effect of the BTX manifested. Almost immediately after the second injection, the sialocele disappeared, although the patient had resumed oral nutrition after the first injection. The patient was discharged 10 days after the first botox injection. In the more than 12 months that she has been under follow-up care, there has been no evidence of recurrent sialocele or facial nerve injury related to the BTX injection.

\section{DISCUSSION}

A parotid sialocele is a salivary cavity arising at the expense of a

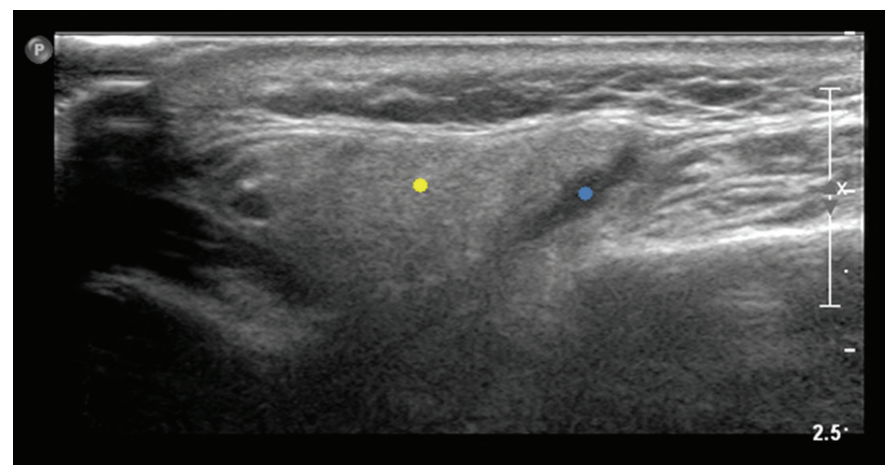

Fig. 3. Ultrasonographically guided injection of botulinum toxin into the parotid gland. Yellow circle: parotid gland. Blue circle: needle inserted into the gland.

parotid duct. It is typically post-traumatic or iatrogenic after parotid surgery [1]. The diagnosis is eminently clinical, using the physical examination and clinical history [2]. Fine-needle aspiration confirms the diagnosis with a high level of amylase originating from the saliva. An imaging study, including high resolution ultrasonography, is considered helpful for identifying ductal injury, size, location of the cyst, and fistula formation. Sialography is also considered a mainstay for diagnosis and evaluation but may increase the pressure in the sialocele, causing rupture and fistula [3]. Management for sialocele is diverse from conservative treatment to radical surgical modalities, and factors to be considered are time elapsed since injury, gland site affected, trauma mechanism, and experience of the surgeon [4]. However, conservative management is usually given initially unless obvious ductal injury is suspected that necessitates surgical repair. The first-line methods include successive percutaneous aspirations, compress application, and parenteral nutrition to reduce autonomous salivary stimulation. Antisialogogue medications including anticholinergic agents are also administered to inhibit the action of acetylcholine at the postganglionic nerve endings of the parasympathetic nervous system. However, side effects can included xerostomy, constipation, photophobia, tachycardia, and urinary retention [5]. When conventional conservative management fails, BTX is considered. BTX blocks acetylcholine release, thereby inhibiting neurotransmission at the secremotor parasympathetic autonomic nerve ending responsible for salivation [6]. Marchese Ragona et al. [7] and Vargas et al. [8] have also reported the use of BTX in treating parotid sialocele resistant to conventional modes of treatment. They have asserted that BTX is highly effective and non-invasive for this condition. However, considering the complicated anatomy of the parotid region, consisting of facial nerves and vessels, blind injection of BTX can be hazardous and burdensome, especially for unexperienced physicians. Real-time ultrasonographic assistance can be utilized to evaluate the exact location and depth of the injection to stay within the superficial parotid gland in order to avoid post-injection facial 
nerve paralysis or vessel damage. Our patient also showed no sign of facial nerve damage. Dessy et al.[9] reported BTX injection for treating parotid fistula after face-lift surgery. Considering the 18,938 face-lift procedures performed in South Korea in 2014, the incidence of sialocele or sialo-cutaneous fistula could be considerable, and physicians should be able to utilize effective methods of botulinum injection when confronting resistant sialocele cases. Numerous studies have reported the use of BTX injection for sialo-cutaneous fistula and sialocele, but a consensus on the exact location, amount, and approach site to prevent facial nerve damage has not been established because of the complexity of the parotid anatomy. To the best of our knowledge, we herein present the first case of ultrasonographically guided injection of BTX for sialocele treatment. We were able to guarantee an easier and safer approach to the parotid gland by use the imaging guidance. For sialocele cases resistant to conventional modes of treatment, BTX A injection can be a valuable option and ultrasonographic guidance enables more precisely locating the gland and safer injection without complications.

\section{PATIENT CONSENT}

Patients provided written consent for the use of their images.

\section{REFERENCES}

1. Laskawi R, Schott T, Mirzaie-Petri M, et al. Surgical management of pleomorphic adenomas of the parotid gland: a follow-up study of three methods. J Oral Maxillofac Surg 1996;54:1176-9.

2. Araujo MR, Centurion BS, Albuquerque DF, et al. Management of a parotid sialocele in a young patient: case report and literature review. J Appl Oral Sci 2010;18:432-6.

3. Medeiros Junior R, Rocha Neto AM, Queiroz IV, et al. Giant sialocele following facial trauma. Braz Dent J 2012;23:82-6.

4. Donoso T, Domancic S, Argandoña J. Delayed treatment of parotid sialocele: a functional approach and review. J Oral Maxillofac Surg 2015; 73:284-90.

5. Parekh D, Glezerson G, Stewart M, et al. Post-traumatic parotid fistulae and sialoceles. A prospective study of conservative management in 51 cases. Ann Surg 1989;209:105-11.

6. Blitzer A, Sulica L. Botulinum toxin: basic science and clinical uses in otolaryngology. Laryngoscope 2001;111:218-26.

7. Marchese Ragona R, Blotta P, Pastore A, et al. Management of parotid sialocele with botulinum toxin. Laryngoscope 1999;109:1344-6.

8. Vargas H, Galati LT, Parnes SM. A pilot study evaluating the treatment of postparotidectomy sialoceles with botulinum toxin type A. Arch Otolaryngol Head Neck Surg 2000;126:421-4.

9. Dessy LA, Mazzocchi M, Monarca C, et al. Combined transdermal scopolamine and botulinum toxin A to treat a parotid fistula after a face-lift in a patient with siliconomas. Int J Oral Maxillofac Surg 2007; 36:949-52. 